\title{
The Speciation of Behavior Analysis
}

\author{
David P. Rider \\ Louisiana State University Medical Center
}

\begin{abstract}
The relationship between the Experimental Analysis of Behavior (EAB) and Applied Behavior Analysis (ABA) has been the subject of several editorials and commentaries in recent years. Various authors have argued that researchers in these two fields (a) have become isolated from each other, (b) face different requirements for survival in their respective fields, and (c) possess different skills to meet those requirements. The present paper provides an allegory for the relationship between EAB and ABA in terms of biological speciation. The conditions that have changed the relationship between EAB and ABA are parallel to those responsible for biological speciation: (a) isolation of some members of a species from the rest of the population, (b) different contingencies of survival for members of the two separate groups, and (c) divergence in the adaptive characteristics displayed by the two groups. When members of two different groups, descendants of common ancestors, no longer are capable of producing viable offspring by interbreeding, the different groups then represent different species. To the extent that members of the EAB group and members of the ABA group interact with each other only trivially, they each represent allegorically different species. Changes in the relationship between EAB and $\mathrm{ABA}$ are part of a natural process that takes place in many other sciences, and the course of that process can hardly be reversed by us.
\end{abstract}

Key words: applied behavior analysis, experimental analysis of behavior, applied research, basic research, evolution, speciation

Looking to the future, we can predict that the groups of organic beings which are now large and triumphant, and which are least broken up, that is, which have as yet suffered least extinction, will, for a long period, continue to increase. But which groups will ultimately prevail, no man can predict; for we know that many groups, formerly most extensively developed, have now become extinct. (Darwin, 1859, p. 134)

A schism between basic and applied research was the subject of an editorial published in a multidisciplinary journal whose objectives include both pure scientific research and service-oriented applications (Wilcox, 1987). According to the editorial, the schism has contributed to the failure of the service profession to keep pace with rapid developments in basic research. Controversy between basic and applied researchers over current

I thank Jane B. Atwater, Donald M. Baer, William Buskist, Mathew Casado, Brian J. D'Angelo, Richard J. DeGrandpre, Edmund Fantino, Nora N. Kametani, K. L. McManis, Edward K. Morris, Eileen P. Rider, and Jon D. Ringen for helpful comments on earlier versions of this manuscript. The opinions expressed herein do not necessarily reflect those of anyone.

Reprints can be obtained from the author, Louisiana State University Medical Center, School of Allied Health Professions, 1100 Florida Avenue, Building 119, New Orleans, Louisiana 70119. best practices pits good science against expedient practice. The schism

is clearly a major limiting factor in the developmental process that must be overcome if the field is to reach maturity. Although the schism is not likely to disappear, the development of an interactive relationship between the academic and the practitioner is required. Recognizing the fundamentally different mind-sets of each is a necessary first step toward this crucial mutualism.

The academic and the practitioner respond to quite distinct environments and are motivated by broadly differing views and experiences. The former is primarily concerned with advancing knowledge, while the latter is concerned with applying knowledge. ... The former strives to reduce the uncertainty about how nature works, the latter often must proceed despite this uncertainty. Most important, the academic scientist is usually not constrained by the immediacy of decisions that often have significant political, economic, legal, and social consequences. The ... practitioner routinely must make such decisions. (Wilcox, 1987, pp. 188-189)

The relationship between basic and applied research is a popular subject in scientific fields, like behavior analysis, where that relationship is tenuous. Journals publish editorials and commentaries that usually are aimed at helping to reestablish a relationship between basic and applied researchers. They rarely do. But the editorials and commentaries are fun to read and the lively discussion attracts the 
attention of people who work in those fields, thereby helping to inform them of changes taking place. Educators have attended to the schism in their field for about 20 years (e.g., Ausubel, 1969; Bain \& Groseclose, 1979; Brady, Gunter, \& Langford, 1985; Drew \& Buchanan, 1979; Fife, 1979; Kerlinger, 1977; Krathwohl, 1977; Prehm, 1976). Behavior analysts have attended to the schism in their field for about 10 years (e.g., Baer, 1981; Birnbrauer, 1979; Branch \& Malagodi, 1980; Deitz, 1978; Epling \& Pierce, 1983, 1986; Hayes, 1978; Hayes, Rincover, \& Solnick, 1980; Michael, 1980; Pierce \& Epling, 1980; Poling, Picker, Grossett, Hall-Johnson, \& Holbrook, 1981). Judging from the solicitous editorial by Wilcox (1987), conservation biologists are just beginning to notice the schism in their field.

The isolation of populations of workers in different segments of a schismatized field provides an apt allegory for the result of such a split. The workers in each segment of the field are aware of the workers in the other segment of the field, but communication across whatever it is that separates them is difficult. Thus, while workers on each side of the division understand very well what they collectively are doing, they do not understand very well what workers collectively are doing on the other side of the division.

Previous editorials and commentaries on the field of behavior analysis already have laid a solid foundation for the allegory. Deitz (1978), Pierce and Epling (1980), and Epling and Pierce (1983) referred to the "separation" of Applied Behavior Analysis (ABA) from the Experimental Analysis of Behavior (EAB). Hayes et al. (1980) described ABA as "a fully recognized subarea of behavioral science" (p. 275). Michael (1980) and Epling and Pierce (1986) referred to the "isolation" of ABA from EAB and Michael (1980) to the "loss of contact" between ABA and EAB. Hayes (1978) referred to the "dimensions which divide the field" (p. 28). Poling et al. (1981) went so far as to suggest that ABA workers and $\mathrm{EAB}$ workers are not even working in the same field anymore, that $\mathrm{ABA}$ and $\mathrm{EAB}$ "are largely separate, insular fields" (p. 93). They were blunt about the isolation of workers in these fields: "The gulf between applied behavior analysis and some areas of the experimental analysis of behavior is wide and unbreachable" (p. 102).

Populations that are isolated from each other often face radically different contingencies of survival. The consensus is that this is true for ABA and EAB populations. "Applied research has different requirements from basic research" (Azrin, 1977, p. 141). According to Azrin (1977), the guiding principle for basic research is understanding of behavior; the guiding principle for applied research is cure. According to Deitz (1978), "the basic goals of a science differ from those of a technology" (p. 805). According to Michael (1980), "most of the growth in opportunities has taken place in the applied areas, and the people who take such jobs soon come under the control of the practical needs and demands of those areas" (p. 9). According to Baer (1981), behavior analysts and applied behavior analysts sell the products of their work to different consumers:

Increasingly, it seems to me, universities think that they should hire one of each. Since universities almost never hire two of anything, for fear that they might breed, the universities must assume that (apart from themselves) the markets for behavior analysts and applied behavior analysts are indeed different. I think that they are correct in this. (p. 90)

Whether worded as requirements, goals, practical needs and demands, or markets, the implication is the same: ABA workers face different contingencies of survival on their side of the field than EAB workers face on theirs.

As natural environments differ, so do the adaptive characteristics of organisms that promote survival in those environments. Adaptive characteristics may include such phenotypic features as size, color, anatomy, physiology, and especially for the present illustration, behavior. When a population of anything is split into isolated regions that impose different contingencies of survival, the outcome is never ambiguous: Each population either survives or perishes. Sur- 
vival always hinges on the ability of individuals to meet the demands of the natural environment and to do so in sufficient numbers to propagate their own kind. Individual members of a population either have adaptive characteristics that are good enough to meet the demands of their natural environment or they do not. If enough of them do, their kind will survive. If they do not, then either they change or their natural environment will kill them. If enough of them happen to change in ways that happen to be adaptive in that natural environment, then their kind will continue to survive. If not, they will die. Both populations of $A B A$ workers and $E A B$ workers have propagated their own kind, so far. Therefore, each population has adaptive characteristics that are good enough to meet the demands of its respective natural environment, so far.

The natural environment inhabited by EAB workers has not changed much, except that it has become increasingly mathematical and theoretical and no longer has much respect for cumulative records. The natural environment inhabited by $\mathrm{ABA}$ workers is considerably different. It is not clear whether that environment has changed since they started calling themselves ABA workers (as in Baer, Wolf, \& Risley, 1968) or whether that environment always has been different, but that does not matter. The point is that it is different. ABA workers do not have characteristics that would meet the demands of the natural environment of EAB workers; neither do EAB workers have characteristics that would meet the demands of the natural environment of ABA workers, but that does not matter. All that matters is that each group has characteristics that are good enough to meet the demands of its own natural environment.

The consensus is that this analysis is correct. Michael (1980) listed numerous demands of the natural environment of ABA workers and he asserted that ABA workers meet them. He also listed several demands of the natural environment of $\mathrm{EAB}$ workers and he asserted that $\mathrm{ABA}$ workers neither have to meet them nor do meet them. Baer (1981) suggested that the demands of the natural environments of $E A B$ workers and $A B A$ workers are so different that $A B A$ represents a new, self-contained discipline "almost as easily divorced from behavior analysis as behaviorism was from physiology and mentalism" (p. 90). Poling et al. (1981) mailed questionnaires about the schism between ABA and EAB to the editorial staffs of the Journal of the Experimental Analysis of Behavior and the Journal of Applied Behavior Analysis (JABA). A $J A B A$ editor commented that "contingencies have operated to create a greater separation of the fields than was the case in the past. Some of these contingencies are important ones and, for better or worse, unalterable" (p. 100). Pierce and Epling (1980) argued that

analytical behavior is at low levels in applied analysis while cure-help behavior is at high strength. This low proportion of scientific behavior is apparently related to cure-help contingencies set by institutions and agencies of help and the editorial policies of $J A B A$ itself. (p. 1)

Some authors have argued that some of the characteristics of ABA workers that formerly were adaptive not only are no longer adaptive in their current environment, they are maladaptive. Michael (1980) explained that demands of the marketplace discourage practices that promote the cause of behaviorism and the generality of behavioral principles:

It is not sufficient, nor required, that they contribute to the generality of existing behavioral principles, or further the cause of behaviorism. This means that practical outcome becomes more important than knowing about the way variables affect behavior. Component analysis is not necessary, and if costly or time-consuming it is actually a hindrance. (pp. 9-10)

Pierce and Epling (1980) asserted: "The present operating contingencies which control the behavior of researchers in applied analysis make it unlikely that scientific behavior ... will be favored" ( $p$. 8). Branch and Malagodi (1980) illustrated how mentalism can become adaptive and radical behaviorism maladaptive in the new environment:

Individual fledgling behaviorists have usually found themselves surrounded by mentalists who eventually come to control the behavior of the poor 
former behaviorist. These mentalists pay lip service to some of our more powerful methods to demonstrate to us their open-mindedness, and then reinforce our open-mindedness in accepting mentalistic concepts. They take advantage of our pregraduate school, excessively mentalistic history, and soon (often before the tenure deadline) the former behaviorist is acknowledging the central role of cognitions (i.e., mental events) in the determination of behavior. (p. 36)

Some authors have recommended that workers acquire additional characteristics. Branch and Malagodi (1980) recommended stronger commitment to behaviorism and weaker commitment to mentalism. Deitz (1978) recommended that ABA workers become more analytical and investigative. Birnbrauer (1979) recommended that all workers and even the consumers of behavior analysis be educated in the principles, methods, and procedures of both basic and applied behavior analysis (whether they like it not). Michael (1980) recommended that all workers learn as much as possible about the philosophy of behaviorism and both the basic and the applied sciences of behavior, read almost everything Skinner has ever written, and stop ignoring the role of rule-governed behavior.

As attractive as some of these recommendations might seem to some people, none of them will be heeded. Adaptive characteristics are by-products of contingencies of survival. But contingencies of survival are not established by proclamation; they are established by the natural environment. And it may be that a stronger commitment to behaviorism, becoming more analytical, being educated in principles, methods, and procedures, and learning more about philosophy, science, and Skinner, all are characteristics that would promote the survival of workers who acquire them. Whether they truly are adaptive is an empirical question that probably never will be answered. Only the natural environment could pose-or answer-such a question. So the only recommendation that will be accepted is Baer's (1981), "that we simply continue doing what we are doing, and are going to do anyway no matter what I recommend" (p. 91).

What has happened to behavior anal- ysis also happened to education and appears to be happening to conservation biology. Many of the organisms in those schismatized fields have noticed how much some of them have changed, would like to go back to the old field in which some of them grew up so happily, and pretend that the contingencies of their survival are different from what they actually are. What happened to behavior analysis, education, and conservation biology is a natural phenomenon that happens to virtually every science that has practical applications. The history of science is full of examples. The progenitor of engineering is physics; the progenitor of accounting is mathematics; the progenitor of medicine is biology; the progenitor of cooking is physical chemistry (Baer, 1987). (This is not actually literally true because each of these applied disciplines to some extent relies on several different basic sciences. The history of science also includes instances in which basic science was advanced by knowledge that had been put to practical use for years. I invoke simplicity for its own sake because the actual, literal, complicated truth implies exactly the same conclusion, but at the cost of considerable boredom.)

Members of applied disciplines typically learn aspects of their ancestral science, but just those aspects that pertain to their applied discipline, and just enough that they can survive in their applied discipline. Sometimes members of applied disciplines learn relatively antiquated but especially useful aspects of their ancestral science to the virtual exclusion of more modern aspects. The relationship between $\mathrm{EAB}$ and $\mathrm{ABA}$ provides one such illustration. As Baer (1981) and Michael (1980) have noted, ABA people are slow to apply new basic findings from EAB; according to Baer (1981), "that is because they have very little need to apply the newest basic findings. They have come upon an element of the old basic findings that for them is a revelation: the principle of positive reinforcement" (p. 88). That principle has undergone various revisions by some basic researchers, revisions that stress relativ- 
ity of reinforcement: the matching law (e.g., Baum, 1974; Herrnstein, 1970). Some authors have advocated the more modern version of that old principle for its accuracy (e.g., Epling \& Pierce, 1983; McDowell, 1982, 1988; Myerson \& Hale, 1984). But since academicians and practitioners, to paraphrase Wilcox (1987), respond to different requirements of different environments, the old-fashioned version of positive reinforcement is still used for most practical purposes. The old version still works very well and it is simpler to work with than the more modern version (e.g., Fuqua, 1984).

The relationship between physics and engineering provides another illustration. Physics is a basic science concerned with matter and energy and their interactions. Engineering is an applied discipline concerned with the application of scientific knowledge, a good portion from physics, to practical ends. For engineers, principles of Newtonian physics are somewhat of a revelation, as positive reinforcement is for ABA people. Newtonian principles have undergone various revisions by some physicists, revisions that stress relativity of matter and energy. A thorough understanding of Einsteinian or relativity physics is crucial to the survival of modern physicists. It is less important to engineers because of their concern with the practical. For example, some engineers tell constructors how to build things like bridges, but before they can explain how to build a bridge, they first must know how heavy the trucks and cars will be that the bridge must support. If an engineer asked Newton how heavy a moving truck was, Newton could tell her. He would be wrong, of course, but the magnitude of his error would be so small as to be trivial. But, if an engineer asked Einstein how heavy a moving truck was, Einstein would ask how fast it was moving. Despite its antiquity and modest inaccuracies, Newton's theory remains useful for many practical purposes among engineers, and even among physicists. Indeed, Hawking (1988) has asserted that physicists

still use Newton's theory for all practical purposes because the difference between its predictions and those of general relativity is very small in situations that we normally deal with. (Newton's theory also has the great advantage that it is much simpler to work with than Einstein's!) (p. 10)

In practical matters, simplicity is an important consideration.

The different professional requirements of basic and applied disciplines are reflected in different training requirements for students. To learn their professional repertoires, engineers do not go to graduate school in physics; they go to engineering school where they learn very little about modern theoretical or experimental physics, a little more about Newtonian physics, and a lot about engineering. Similarly, accountants do not go to graduate school in mathematics to learn their repertoires; they go to accounting school where they learn a little bit about mathematics and a lot about accounting. They do so because they must know a lot about accounting in order to survive in an accounting environment, and they do not need to know much about mathematics. For the same reasons, medics and cooks go to medical school and wherever cooks go, respectively, to learn little bits about biology and chemistry and a lot about medicine and cooking, respectively.

Members of the basic sciences typically learn nothing at all about the applied disciplines that evolved from their science because an understanding of those applied disciplines is not crucial to their survival in basic science. Physicists, mathematicians, biologists, and chemists study engineering, accounting, medicine, or cooking only if they happen to be interested in such things.

EAB and ABA people typically learn their repertoires in separate graduate programs, if not separate graduate schools, just as basic and applied people of other disciplines typically do. EAB and ABA people read different books and journals once they are finished with their respective graduate programs, as Poling et al. (1981) have shown, just as basic and applied people of other disciplines do. When they are finished with whatever schools they attended, physicists, engineers, mathematicians, accountants, biologists, 
medics, chemists, and cooks read the journals in vogue in their respective fields and only whatever else happens to interest them. Chemists normally do not read cooking journals and cooks normally do not read chemistry journals. Neither do any of the others normally read the journals in the fields of their progenitor or their progeny, unless those journals happen to interest them.

So far as I can tell, chemists and cooks never talk about whatever it was that split their field. So far as I can tell, neither do physicists and engineers, mathematicians and accountants, nor biologists and medics. Perhaps it is because those fields were split such a very long time ago, so long ago that no one remembers and no one cares about the good old days. When they are reminded that they once were related, they still do not care.

The changes that have taken place in behavior analysis are part of a natural process that has taken place in many other sciences, and the course of that process can hardly be reversed by us. Perhaps some members of the $A B A$ population and some members of the EAB population (as some educators and some conservation biologists) still care about the schism in their field because it occurred such a very short time ago, so short a time that many of them still remember and still care about the good old days. Perhaps some day ABA members and EAB members will have to be reminded that they once were related and, even when reminded, they still will not care.

An interesting thing happens in the real world when a group of organisms becomes geographically isolated from the rest of the population and faces new, radically different contingencies of survival. Geographic isolation refers broadly to any environmental factor that inhibits gene flow between the two groups of members of the same species (see Mayr, 1942, 1976; Wagner, 1868; or any good text on evolutionary biology). The isolated group probably must be fairly few in numbers, something on the order of a thousand or so (see Eldredge, 1985; Eldredge \& Gould, 1972 ; or any good review of what biologists call "punctuated equilibria" and "adaptive radiation"). The new survival contingencies place members of the small, isolated group at a relative disadvantage. Usually some members of the group manage to survive long enough to propagate another generation, some members of which survive long enough to propagate yet another. But their numbers typically decline over successive generations until, eventually, the group is eliminated. Sometimes, however, the new survival contingencies of the new environment favor some members of the isolated group who happen to be different from the rest of the group. Sometimes some members of the isolated group, or members of successive generations of that group, propagate new and different organisms through genetic mutation of phenotypic variation that happen to have adaptive characteristics that are more suitable to the new environment than those of their parents. These new, altered organisms with their new adaptations do not face the same disadvantage as their ancestors and so are more likely to survive long enough to propagate their own kind. When they do, they begin a new group of organisms that, while still sharing a considerable portion of the former group's genetic heritage, is different from the original group that became isolated a few generations before.

When isolated groups of organisms do leave viable but altered organisms who propagate their own kind, and when their progeny continues to adapt through further genetic mutation or further phenotypic variation in some of their progeny, they eventually become very different from their ancestral population. They become so different that they cannot interbreed with the descendants of their ancestors on the other side of the geographic schism. They could not interbreed even if the schism disappeared, even if they wanted to interbreed. It probably takes a fairly brief period of time (relative to the three and a half billion years or so of life on this planet), something on the order of 5,000 to 50,000 years. (Incidentally, biologists know this from the work of Ronald A. Fisher, an evolutionary biologist who studied mechanisms of genet- 
ics and who happened to be a whiz at statistics.) When members of a group of organisms become so different that they no longer can produce viable offspring by interbreeding with the descendants of their ancestors on the other side of the schism, biologists call them a new species.

The allegorical schism that isolates the ABA population from the EAB population disappears temporarily each year at the Association for Behavior Analysis conference. At the conference, gene flow between the two populations is not inhibited by any environmental factor. Individual members of each population are thrust together in the same hotel like goats and llamas at a petting zoo. At the conference, EAB organisms spend most of their time attending paper sessions, exchanging verbal behavior, and having lunch with other EAB organisms; their intercourse is almost exclusively with each other. The same pattern of behavior can be observed with most ABA organisms.

The speciation of behavior analysis is an allegory in which changes in behavior analysis are represented symbolically in terms of biological speciation. The conditions that foster biological speciation are in many ways parallel to the conditions that have changed behavior analysis. This allegory is justified to the extent that those conditions truly are parallel.

One aspect of the allegory in which conditions are not parallel involves the manner by which the so-called adaptive characteristics of organisms are transmitted. Adaptive characteristics of real organisms are transmitted genetically to their offspring. It is a process that takes place between generations. Adaptive characteristics of behavior analysts are transmitted allegorically to their students by lectures, conversations, readings, etc. If this were the only means by which information could be transmitted among behavior analysts, then it would be parallel to the intergenerational process of genetic transmission: Information would be transmitted from teacher to student as genetic information is transmitted from parent to offspring.
But the transmission of information among behavior analysts clearly is not restricted to a teacher-student process. Information theoretically could be transmitted by anyone to anyone. To be a goat or a llama, one must have parents who are goats or llamas. To be a behavior analyst, one need not necessarily have teachers who are behavior analysts; virtually anyone can join. Furthermore, having become an $\mathrm{EAB}$ member does not preclude a person from becoming an $\mathrm{ABA}$ member. A few behavior analysts are both. Many more behavior analysts could be both if they only read the right books and journals (Michael, 1980). In fact, because of the myriad ways in which such information can be transmitted, behavior analysts also could become medics or cooks. A goat cannot become a llama simply by reading the right books and journals.

A second aspect of the allegory in which the parallelism of conditions might be contested involves the mutability of socalled contingencies of survival. For real organisms in the real world, survival contingencies represent conditions in the environment that govern whether individuals live long enough to reproduce. Such contingencies are largely immutable: Organisms (or species) may adapt to the physical and climatic conditions of an environment, its resources and its predators, but they have little control over such conditions. In the allegory, "survival contingencies" is used symbolically to represent conditions in the professional environment of behavior analysts that govern, for examples, whether individuals find jobs, publish papers, recruit students, retain verbal behavior indigenous to behavior analysis, and whatever else may contribute to the perpetuation of a scientific discipline-or culture-known as behavior analysis. These are not survival contingencies at all (except in the symbolic, allegorical sense); they are reinforcement contingencies. In contrast to true survival contingencies, reinforcement contingencies are subject to change: ABA organisms, in fact, are notably adapted to doing just that.

Such a difference in the mutability of 
survival contingencies would strain the allegory because it would place behavior analysts in a fundamentally different position from other organisms with respect to the contingencies that govern their lives. Survival contingencies affecting real organisms and real species are beyond their direct control; reinforcement contingencies affecting the behavior of behavior analysts seem to be well within the purview of their control. Thus, from this perspective, behavior analysts are empowered to intervene and change contingencies of reinforcement to alter the course of their evolution whereas real biological organisms are not empowered to intervene and alter the course of their evolution. The cultural evolution of behavior analysis proceeds with the tacit consent of behavior analysts; the biological evolution of species proceeds independently.

The evolution of behavior analysis could be altered if an appropriate intervention were to be designed and implemented. Designing and implementing interventions that change reinforcement contingencies and thereby modify operant behavior are hallmarks of behavior analysis. Nonetheless, designing, implementing, and changing things do not make behavior analysts prime movers. The designing of interventions by behavior analysts is itself operant behavior subject to control by reinforcement contingencies just as any other operant behavior is. An intervention capable of altering the entire field of behavior analysis is within the realm of possibility. But it could be implemented only by someone (or some group) with sufficient control over the entire field of behavior analysis, and only if relevant contingencies in the environment provoke that person (or that group) into intervening.

\footnotetext{
In application, behaviors are analyzed and changed because they constitute a problem for someone capable of changing them or getting someone else to change them. Behavior problems comprise both excesses of some behaviors and insufficiencies of others, but their essence as problems is that someone complains effectively enough about them to provoke a behavior-change program. (Baer, 1986, p. 121)
}

It may appear to some people that they have ultimate control over behavior because they are so good at modifying it. But they are only mediators between the environment that controls their behavior and the environment that controls the behavior of their clients. The people who design behavior-change programs are as much a part of the causal stream of the natural environment as the people with behavior problems and the people who complain about them. Surely behavior analysts understand that this doctrine is fundamental: "No one steps outside the causal stream. No one really intervenes" (Skinner, 1974, p. 206).

This doctrine should be no surprise to either the ABA group or the EAB group. Despite their many differences, members of each group still understand similarly that the behavior of all organisms is controlled not by free will but by the environment. Members of each group perpetuate the doctrine by teaching their students that, just as contingencies of survival select phenotypes embodied in organisms that are good enough to survive, contingencies of reinforcement select behavior that is good enough to be reinforced. Organisms respond to those contingencies as functions of their phylogenetic and their ontogenetic histories. Species cannot change their genetic makeup and organisms cannot change their reinforcement history just because such changes would make them even better than they already are at surviving and obtaining reinforcers. Students learn that behavior is modified only by the environment, and so they must have control of relevant aspects of the environment in order to modify behavior. They learn that their efforts to modify the behavior of their subjects or their clients do not arise from within, but are likewise controlled by relevant aspects of their environment. Some students even learn to modify their own behavior by making changes in their own environment. They also learn that the ultimate source of control lies beyond their reach, that even their efforts at self modification do not arise from within, but are controlled by the environment. 
Determinism on such a personal level frightens some people. Skinner (1957) prepared us to deal with it more than 30 years ago:

We must not turn back because the prospect suddenly becomes frightening. The truth may be strange, and it may threaten cherished beliefs, but as the history of science shows, the sooner a truth is faced, the better. No scientific advance has ever actually damaged man's position in the world. It has merely characterized it in a different way. Indeed, each achievement has in a sense increased the role which men play in the scheme of things. If we eventually give a plausible account of human behavior as part of a lawfully determined system, man's power will increase even more rapidly. Men will never become originating centers of control, because their behavior will itself be controlled, but their role as mediators may be extended without limit. (pp. 459460)

Behavior analysts could alter the course of their evolution, theoretically at least, by systematically changing their professional behavior, as so many authors have urged. (So could the members of any real biological species alter the course of their evolution by systematically changing their mating behavior.) Birnbrauer (1979), Branch and Malagodi (1980), Michael (1980) and several others have proffered cogent arguments and some specific suggestions for change, for a renewed, closer relationship between EAB and ABA. Epling and Pierce $(1983,1986)$, McDowell $(1982,1988)$, and Myerson and Hale (1984) have shown how aspects of each field could benefit the other. Yet despite cogent arguments and specific suggestions for change, very little has changed in recent years: $\mathrm{EAB}$ and $\mathrm{ABA}$ continue as largely separate, insular fields. This evidence suggests that the people who want a reunification of behavior analysis do not control the relevant contingencies, and so they cannot alter the course of evolution in behavior analysis. If anyone actually does control relevant contingencies in someone's natural environment, and that environment is isolated from the rest of $A B A$ or $E A B$, then perhaps the course of evolution could be altered in those organisms who inhabit that environment-at least until they graduate and move to another environment.

An allegory should do more than pro- vide a figurative description of one subject in terms of another. It should illuminate the principle subject by casting it in a novel light. Allegories can be especially useful in casting a more objective light on subjects that otherwise evoke emotional reaction, subjects in which people have vested interest. The present allegory may help us to see our past, the changes that have taken place in behavior analysis, as a lawful product of the natural environment that we have mediated. The allegory also may provide a glimpse into the future, a future that no one really knows, but can be forecast according to what is known of the past.

Many authors have recommended changes in behavior analysis on the assumption that such changes would make behavior analysts more adaptive and thereby better able to survive. An implicit goal is to foster characteristics that are optimal in the natural environment of behavior analysts. However, no one knows for certain what is optimal, especially in a natural environment that keeps changing. Further, nature does not select what is optimal; it selects what is good enough:

We may be amazed at the intricate adaptations of some organisms, but for the most part living creatures are relatively inefficient machines. The energy-procuring behaviors and devices of organisms are better seen as "good enough"- to keep organisms alive and to allow them to reproduce-than as manifestations of ultimately perfect design. (Eldredge, 1985, p. 148)

Mammals, for example, have remarkably efficient digestive systems that convert wide varieties of complex organic material into simple, usable organic material (so cells can be mended and regenerated) and energy (so behavior can be emitted). Digestive systems of mammals also filter most of the useless waste and some of the toxic materials commonly found in complex organic material, disposing of it through various body orifices. But digestive systems do not filter all toxic materials. Some toxins, unwittingly eaten by some mammals, invariably kill them. Perhaps a digestive system that more perfectly filtered toxic material 
would be more adaptive for all of us. But the imperfect one we have is good enough for most of us to survive long enough to reproduce.

Similarly, the cure-help behavior so common among ABA organisms is a remarkably efficient adaptation that cures a lot of problems and helps a lot of other organisms (Pierce \& Epling, 1980). Sometimes the relatively simple cure-help repertoire fails to cure or help. Perhaps a more complex behavioral repertoire that included an analytic component and stricter adherence to behavioral principles would be even better at curing and helping. But the imperfect cure-help fixed action pattern is good enough for most of its practitioners to survive long enough to teach their students how to do it, thereby propagating their own kind.

Adaptiveness is a concept that has meaning only with respect to a particular environment. A characteristic that is adaptive in one environment, even optimally so, is not necessarily adaptive in another. As environments inevitably change in time, so does adaptiveness. Behavior is not adapted to events in the future, but to the past: "Lineages do not learn in time to survive better. ... Species are adapted to their ambient environments, not to some future possibilities" (Dobzhansky, Ayala, Stebbins, \& Valentine, 1977 , p. 342). No one can predict with certainty how the natural environment will change, and so, to paraphrase Darwin (1859, p. 134), no one can predict which groups will prevail and which will become extinct.

Behavior analysts may scheme to preserve the discipline forever, but perpetual preservation is unrealistic: "Extinction is the ultimate fate of all lineages" (Gould, 1983 , p. 344). Nothing lasts forever-not even behavior analysis. Its demise will not be the fault of any behavior analyst; it will be because its natural environment will have changed too fast for behavior analysts to acquire suitably adaptive characteristics to meet the new demands. We cannot preserve forever a natural environment that will preserve us forever any more than we can preserve a natural environment for the California condor.
Someday we will lose our natural environment, just as the condor has, and some of us will take refuge in a few universities as last bastions, just as representatives of other endangered species take refuge in a few zoos. Sooner or later, we will lose this place.

Said the condor
to the praying mantis
We're gonna lose this place
just like we lost Atlantis
- N. Young (1982)

\section{REFERENCES}

Ausubel, D. P. (1969). The nature of educational research. In W. J. Gephart \& R. B. Ingle (Eds.), Educational research: Selected readings (pp. 513). Columbus, OH: Charles E. Merrill.

Azrin, N. H. (1977). A strategy for applied research: Learning based but outcome oriented. American Psychologist, 32, 140-149.

Baer, D. M. (1981). A flight of behavior analysis. The Behavior Analyst, 4, 85-91.

Baer, D. M. (1986). In application, frequency is not the only estimate of the probability of behavioral units. In T. Thompson \& M. D. Zeiler (Eds.), Analysis and integration of behavioral units (pp. 117-136). Hillsdale, NJ: Lawrence Erlbaum Associates.

Baer, D. M. (1987). Weak contingencies, strong contingencies, and many behaviors to change. Journal of Applied Behavior Analysis, 20, 335337.

Baer, D. M., Wolf, M. M., \& Risley, T. R. (1968). Some current dimensions of applied behavior analysis. Journal of Applied Behavior Analysis, 1, 91-97.

Bain, H. P., \& Groseclose, J. R. (1979). The dissemination dilemma and a plan for uniting disseminators and practitioners. Phi Delta Kappan, 61, 101-103.

Baum, W. M. (1974). On two types of deviation from the matching law: Bias and undermatching. Journal of the Experimental Analysis of Behavior, 22, 231-242.

Birnbrauer, J. S. (1979). Applied behavior analysis, service, and the acquisition of knowledge. The Behavior Analyst, 2(1), 15-21.

Brady, M. P., Gunter, P., \& Langford, C. A. (1985). Why aren't research results in practice? In M. P. Brady \& P. L. Gunter (Eds.), Integrating moderately and severely handicapped learners: Strategies that work (pp. 282-294). Springfield, IL: Charles C. Thomas.

Branch, M. N., \& Malagodi, E. F. (1980). Where have all the behaviorists gone? The Behavior Analyst, 3(1), 31-38.

Darwin, C. (1859). On the origin of species by means of natural selection, or the preservation of favoured races in the struggle for life. London: John 
Murray. Facsimile of 6th ed., New York: P. F. Collier and Son.

Deitz, S. M. (1978). Current status of applied behavior analysis: Science versus technology. American Psychologist, 33, 805-814.

Dobzhansky, T., Ayala, F. J., Stebbins, G. L., \& Valentine, J. W. (1977). Evolution. San Francisco: W. H. Freeman.

Drew, C. J., \& Buchanan, M. L. (1979). Research on teacher education. Teacher Education and Special Education, 2(2), 50-55.

Eldredge, N. (1985). Time frames: The rethinking of Darwinian evolution and the theory of punctuated equilibria. New York: Simon and Schuster.

Eldredge, N., \& Gould, S. J. (1972). Punctuated equilibria: An alternative to phyletic gradualism. In T. J. M. Schopf (Ed.), Models in paleobiology (pp. 82-115). San Francisco: Freeman, Cooper, and Co.

Epling, W. F., \& Pierce, W. D. (1983). Applied behavior analysis: New directions from the laboratory. The Behavior Analyst, 6, 27-37.

Epling, W. F., \& Pierce, W. D. (1986). The basic importance of applied behavior analysis. The $\mathrm{Be}$ havior Analyst, 9, 89-99.

Fife, J. D. (1979). Improving the use of higher education research. Research in Higher Education, 10, 189-192.

Fuqua, R. W. (1984). Comments on the applied relevance of the matching law. Journal of Applied Behavior Analysis, 17, 381-386.

Gould, S. J. (1983). Hen's teeth and horse's toes. New York: W. H. Norton.

Hawking, S. W. (1988). A brief history of time. New York: Bantam Books.

Hayes, S. C. (1978). Theory and technology in behavior analysis. The Behavior Analyst, I(1), 2533.

Hayes, S. C., Rincover, A., \& Solnick, J. V. (1980). The techinical drift of applied behavior analysis. Journal of Applied Behavior Analysis, 13, 275285.

Herrnstein, R. J. (1970). On the law of effect. Journal of the Experimental Analysis of Behavior, 13, 243-266.

Kerlinger, F. N. (1977). The influence of research on educational practice. Educational Researcher, 6(8), 5-12.

Krathwohl, D. (1977). Improving educational research and development. Educational Researcher, 6(4), 8-14.

Mayr, E. (1942). Systematics and the origin of species. New York: Columbia University Press.

Mayr, E. (1976). Evolution and the diversity of life: Selected essays. Cambridge, MA: The Belknap Press of Harvard University Press.

McDowell, J. J (1982). The importance of Herrnstein's mathematical statement of the law of effect for behavior therapy. American Psychologist, 37 , 771-779.

McDowell, J. J (1988). Matching theory in natural human environments. The Behavior Analyst, 11, 95-109.

Michael, J. (1980). Flight from behavior analysis. The Behavior Analyst, 3(2), 1-22.

Myerson, J., \& Hale, S. (1984). Practical implications of the matching law. Journal of Applied Behavior Analysis, 17, 367-380.

Pierce, W. D., \& Epling, W. F. (1980). What happened to analysis in applied behavior analysis? The Behavior Analyst, 3(1), 1-9.

Poling, A., Picker, M., Grossett, D., Hall-Johnson, E., \& Holbrook, M. (1981). The schism between experimental and applied behavior analysis: Is it real and who cares? The Behavior Analyst, 4, 93102.

Prehm, H. J. (1976). Special education research: Retrospect and prospect. Exceptional Children, 43, 10-19.

Skinner, B. F. (1957). Verbal behavior. New York: Appleton-Century-Crofts.

Skinner, B. F. (1974). About behaviorism. New York: Alfred A. Knopf.

Wagner, M. (1868). Die Darwinische theorie und das migrationsgesetz der organismen [The Darwinian theory and the law of migration of organisms]. Leipzig, Germany: Duncker and Humblot.

Wilcox, B. A. (1987). Editorial. Conservation Biology, 1, 188-189.

Young, N. (1982). Like an Inca. Los Angeles: Silver Fiddle Publishing. 